\title{
The Mechanics of the Continuous Rotary Extrusion Process Investigated by FEM-analysis
}

\author{
Henry Valberg, Nijenthan Rajendran and Wojciech Z. Misiolek
}

\begin{abstract}
The continuous rotary extrusion process is a complex metal forming operation, and there is still lack of knowledge regarding the mechanics of the process. Because of this, we decided to use FEM-modelling to characterize and study the thermo-mechanical conditions in the process. Emphasize in our work is on the nature of metal flow and the thermal conditions in the early stages of the process, when the feed-rod material fills up the die cavity and forms the plastic zone. In addition, we investigated when steady state conditions are reached, with respect to the metal flow and the temperature field in the process.
\end{abstract}

Keywords-Contiuous rotary extrusion, FE-modelling, thermo-mechanics, processing of Aluminium

\section{Introduction}

In continuous rotary extrusion (CRE) (1-2), a metal rod is fed into a circumferential groove in a rotary feed-wheel. Here, the rod is coined into the groove by a small coiningwheel. After this, the metal moves with the wheel until it hits a stationary abutment that blocks further rotation of the metal. The abutment "scrapes" the metal out of the groove, so it protrudes radially out from the feed-wheel as a growing lump of metal, which builds up in the front end of the rod. With further feed-wheel rotation, the metal lump moves downwards into a die assembly below the abutment. The assembly consists of dies placed adjacent to the abutment/ wheel in a shoe-like manner. Inside the tooling, there is a die cavity with an orifice at the die center. In addition, there is an inlet gap at the top, adjacent to the feed-wheel, through which more rod material is fed continuously into the process by the wheel.

As the process continues, the metal lump gets bigger, until it fills the die cavities in the tooling. Then, the metal starts to flow out of the die orifice as a product; with crosssectional shape equal to the shape the die hole. A continuous process is established if continuous feedstock is made by joining multiple lengths of rods by pressure welding.

Experimental studies have been conducted on CRE-type of processes. Because the process tooling is closed, it is difficult to study what goes on in the metal inside the plastic zone.

\section{Henry Valberg}

Dep. of Mechanical and Industrial Engineering, Trondheim / Norwegian University of Science and Technology

Norway

Nijenthan Rajendran/ Wojciech Z. Misiolek

Loewy Institute / Lehigh University, Bethlehem, PA USA
This is done, to some degree, by removal and inspection of the metal discard from inside the dies, and the feed-wheel groove, after the process has been stopped (3-5). Information from experimental runs conducted on different types of feedstock in CRE machines is available (6-8), i.e., on feed-rods of alloys of $\mathrm{Al}, \mathrm{Cu}, \mathrm{Mg}$ and $\mathrm{Ti}$.

By means of varying the rotary speed of the feed-wheel, one can see how the speed affects the surface quality of the resulting extruded rod. Such work show that there is an upper limiting rotational speed, not to be exceeded if a sound product, free of surface cracks, is to be obtained in CRE. As in the traditional extrusion process, speed cracking tends to occur, when the process runs too fast. Wheel speeds below a certain level secures a product with good surface quality, and appropriate mechanical properties. Exceeding the critical speed level results in unsound product quality, because then the material develops a dense pattern of transverse surface cracks during outflow from the die

In addition, one has started to model the CRE-process by means of FEM-modelling (4-5, 8-17). This way, additional process information has been collected about the mechanics of CRE. Finally, it is referred to some own previous work (18-19), where we have studied CRE of both Mg- and Alalloys by 3D modelling of the process. Further systematic work is conducted now with these models, and obtained results are reported here.

\section{FEM-model}

The FEM-model developed for the CRE process is shown in Fig.1. Here, the initial stage of the model is shown at the top and the model run up to a stage where the die cavity has been filled, and process conditions have become stable, at the bottom. The length of the feed-rod, extending over the feed-wheel circumference from the abutment to the coining wheel, was coined into the groove in a separate simulation. The last step of the coining simulation was then imported into a new model. Thus, it was not necessary to coin this portion of the rod in our model; instead, the main CRE-model pushes workpiece material by means of the rotating feed-wheel against the abutment already from the beginning.

A more detailed description on how the model was built has previously been reported $(18,19)$, therefore it is referred to these sources. A close-up view through a section of the process, with the abutment and the die arrangement is shown in Fig.2. As seen, the die set consist of three dies stacked on top of each other.

The Lagrangian version of the commercial Deform 3D FEM-program was used to create the models. A number of simulations were run in our study with different setting of the extrusion parameters. 
Proc. of the Eighth International Conference On Advances in Mechanical, Aeronautical and Production Techniques - MAPT 2018 Copyright (C) Institute of Research Engineers and Doctors. All rights reserved.

ISBN: 978-1-63248-147-4 doi: 10.15224/ 978-1-63248-147-4-19
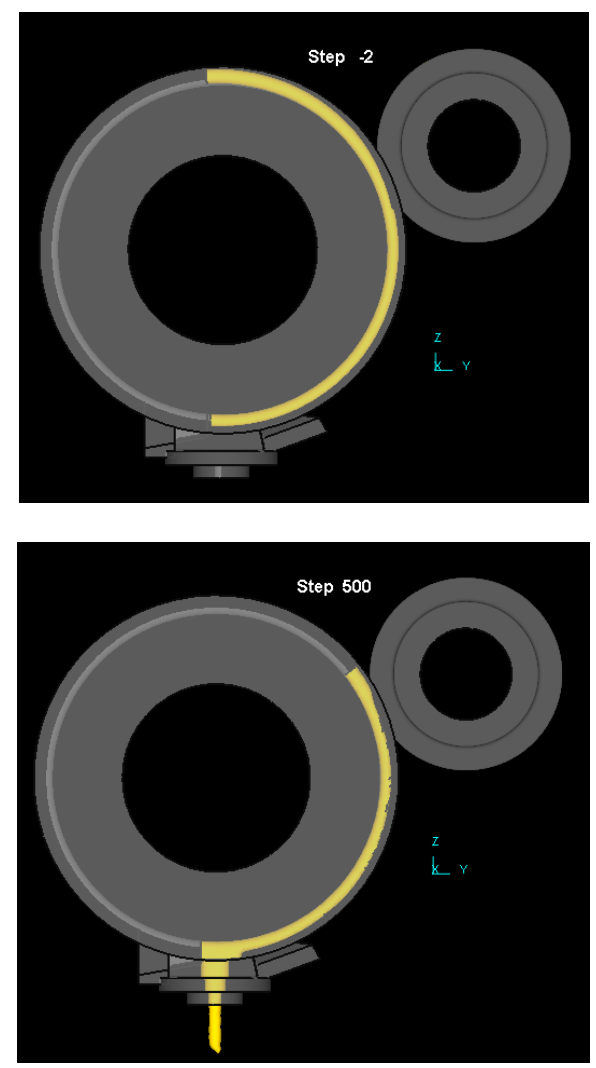

Figure 1. FEM-model initially (top) and run up to step 500 (bottom).

\section{Setting of the simulation parameters}

To study the CRE-process, and investigate how different process conditions like temperature on the dies, friction between workpiece material and dies, rotary speed of the feed-wheel, and the cross-sectional reduction ratio of the feedstock material in the process affect the thermomechanics of CRE, the simulations listed in Table 1 were run.

TABLE I. PARAMETER SETTINGS

\begin{tabular}{|l|c|c|c|c|}
\hline \multirow{2}{*}{ Simulation name } & \multicolumn{4}{|c|}{ Parameter selction } \\
\cline { 2 - 5 } & $\begin{array}{c}\boldsymbol{T}_{\text {Dies }} \\
(\boldsymbol{o C})\end{array}$ & $\begin{array}{c}\boldsymbol{T}_{\text {Abutm. }} \\
(\boldsymbol{o C})\end{array}$ & $\boldsymbol{m}_{\text {Dies/Abutm. }}$ & $\begin{array}{c}\dot{\omega}_{\text {Wheel }} \\
(\boldsymbol{r p m})\end{array}$ \\
\hline Preheat350 & 350 & 100 & $0.7 / 0.6$ & $3^{*}$ \\
Preheat450 & 450 & 100 & $0.7 / 0.6$ & $3^{*}$ \\
500HiFric & 500 & 300 & $2 / 1$ & $3^{*}$ \\
500HiFriStAbutm & 500 & 300 & $2 / 1$ Stick & $3^{*}$ \\
500StickV10 & 500 & 300 & $2 / 1$ & $30^{*}$ \\
500HiFricR2 & 500 & 300 & $2 / 1$ & $3^{* *}$ \\
& & & & \\
\hline
\end{tabular}

* Final rod $8.7 \mathrm{~mm}$ diam. ** Final strip 9 × $2.8 \mathrm{~mm}$

\section{Iv. Results from the analysis}

\section{A. Rotary movement of the feed-wheel}

As shown in Fig.1 (top), the longest initial length of the workpiece rod used in the models was approximately onehalf turn around the feed-wheel. This is what is realistic to use as workpiece length in a Deform 3D model if simulation

time should not be too excessive. This relationship is also depicted in Fig.3 by using of point-tracking in the software. Fig.3 (top) shows initial positions of three material points on the feed-wheel, while Fig.3 (bottom) shows corresponding positions of the points at the end stage of the simulation run.

It is common to quantify the rotation of a body in units of radians. To ease interpretation of this measure of rotational movement in CRE, the graph shown in Fig. 4 was made. As depicted in this figure the maximum feed-wheel rotation in the models was one-half round, which equals an angular rotation of $3.4 \mathrm{Rad}$.

\section{B. Conditions during start-up}

The evolution of the "nose" shape of the lump of metal created in the front end of the rod in the initial stages of CRE is shown in Fig.5 by some recordings from a simulation model. Detail 1, at the top, shows the start-up situation, with the rod coined into the feed-wheel groove, close to the abutment.

Details 2, 3 and 4 in Fig.5 shows how the "lump" of metal builds up in the front end of the feed-rod, and grows in size, as more and more rod material is pushed against the abutment. As the lump grows, it slips off from the abutment and extends into open space inside the die cavity; gradually it evolves into an extended "nose"-like shape. Detail 4, in Fig.5, shows when the nose has grown in length and size, so that the tip of it touches the inlet opening of the die no.3. Shortly after this, the nose touches the edge of this die, and then is forced to flow laterally towards left, until it fills the die bearing channel.

Afterwards, the flow-front of the metal, i.e., the nose becomes approximately stationary; as it becomes stuck in a cold plug-like manner in the bearing channel of die no.3, see detail 5, in Fig.5.

With the flow front resting in the die channel, further metal flow in CRE now takes place by lateral expansion of the lump, until the die cavity inside the tooling has completely filled up with metal. This situation is shown in detail 5, in Fig.5. At this stage, the plug of metal present in the bearing channel of the last die starts to move downwards again, first very slowly as the metal driven forward by the feed-wheel is pushed against the metal now present in the tool cavity.

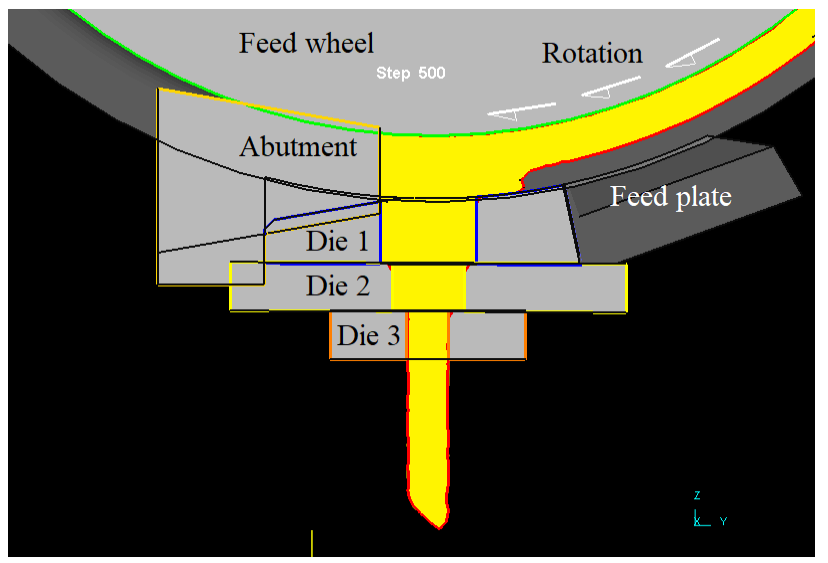

Figure 2. Detail of FEM-model in the die cavity region of the process. 


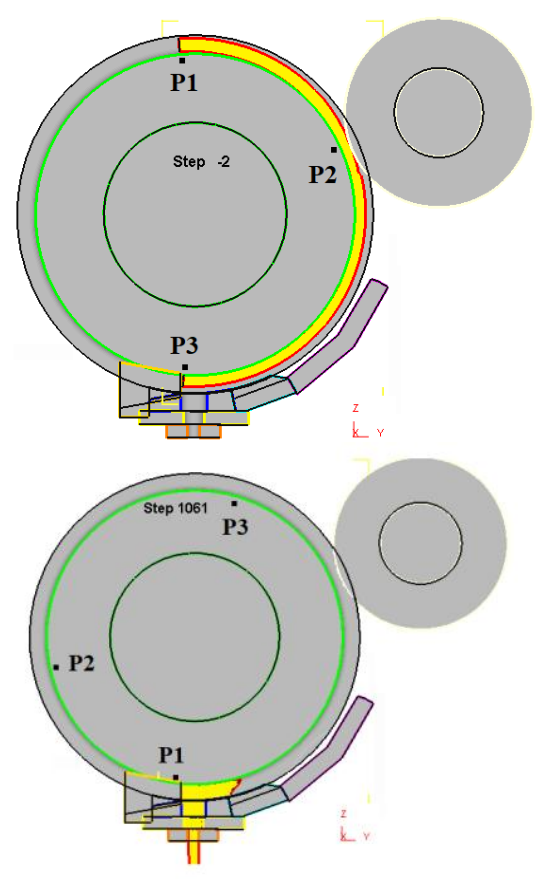

Figure 3. FEA of CRE; initial situation (top), the final situation (bottom) after approximately one-half revolution of the feed-wheel.

The main characteristics of metal flow, at this instant, is that new rod metal in the groove is driven down by the feedwheel into the gap between the wheel and the top die, concurrently as there is some slow forward extrusion of the cold metal plug in the exit of the last die. The lateral metal flow into the gap between the rotating groove of the feedwheel and the top die resembles the upsetting action present in beginning of traditional extrusion; when the billet expands laterally to fill the container. Because of this, it seems natural to name the phenomenon upsetting, or eventually back-flow.

The upsetting phenomenon lasts for a while, as depicted in Fig.5, by details 6, 7 and 8, until the contact length between the upset metal and die no. 1 has reached a certain length, as shown in detail 8 in the figure. Now the contact area between the upset metal and the groove wall of the feed-wheel, is able to provide enough driving force, to push the same amount of incoming material out of the exit of the bottom die, as into the process at the inlet side. Because of this, no more metal now accumulates in the plastic zone of CRE. In terms of net metal flow, the process have reached equilibrium.

\section{Metal flow after establishment of steady state flow}

Simulation pictures showing the longitudinal section through the CRE-process after it has reached equilibrium, are shown by details 9-13 in Fig.6. Actually, the simulation models predicts fluctuations in the metal flow at the inlet side of the plastic zone, where the metal in the groove of the feed-wheel is driven downwards by the feed-wheel, to become upset in the gap between the feed-wheel and the top die.

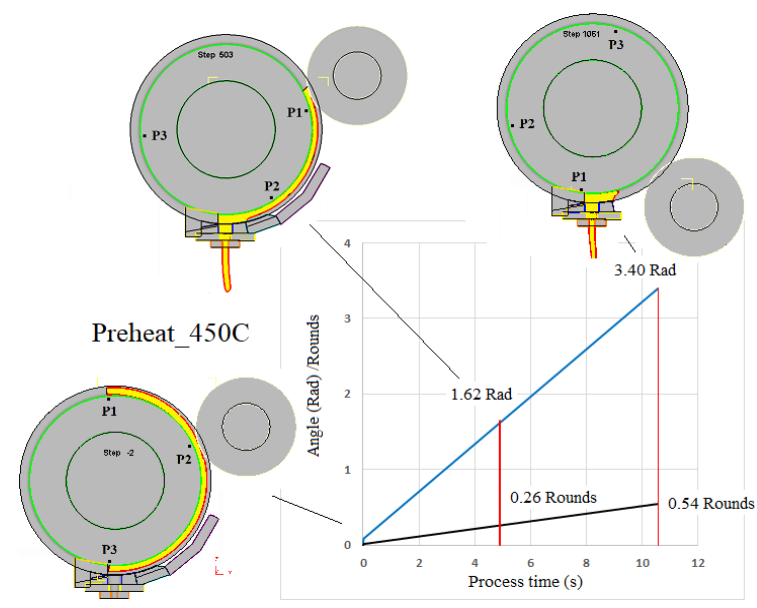

Figure 4. Detail of FEM-model in the die cavity region of the process.

What seems to be a significant trend, in the simulation models, is that during start-up of the process an upset zone of excessive length is created, because of the cold plug-like behaviour of the "nose" in the die exit of the last die. Moreover, as the process progresses further, there is a temperature rise in the cold metal plug in the exit of the last die, as it becomes re-activated in terms of metal flow. Moreover, this causes the length of the upset zone to decrease again. Due to this, the surface at the bottom-side of the feed-rod tends to fold inwards over the dead zone of metal resting against the surface of the die at the top. The fold-in phenomenon here, is visualized by a red circle in detail 10 in Fig.6.
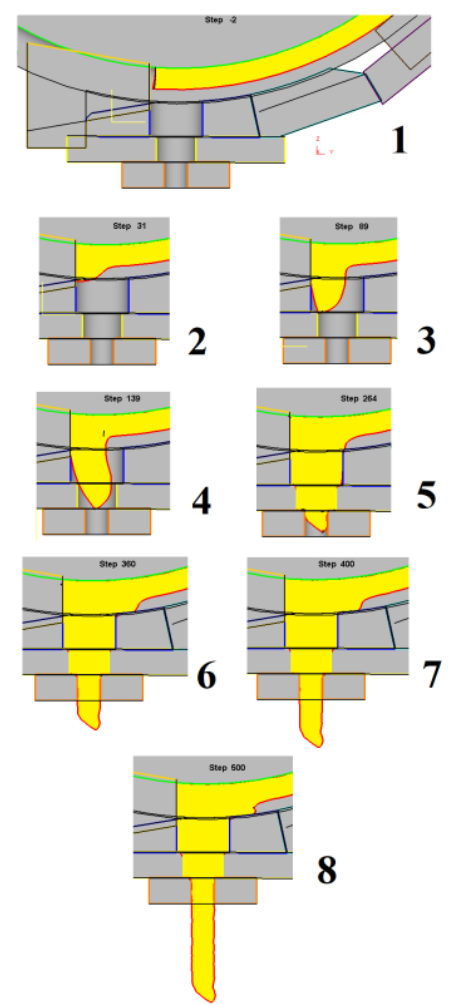

Figure 5. FEM-predicted shape (mid-section) of metal build-up in the region ahead of the abutment, and ifilling of the die cavities, in CRE. 
Proc. of the Eighth International Conference On Advances in Mechanical, Aeronautical and Production Techniques - MAPT 2018 Copyright (C) Institute of Research Engineers and Doctors. All rights reserved.

ISBN: 978-1-63248-147-4 doi: 10.15224/ 978-1-63248-147-4-19
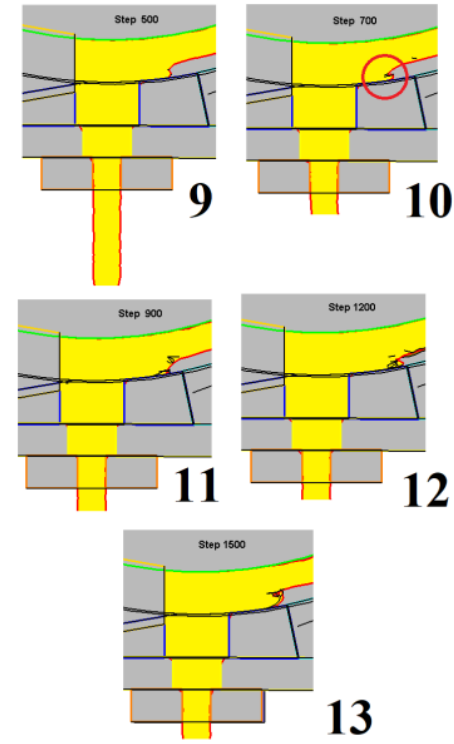

Figure 6. FEM-model prediction after the metal flow in CRE has reached steady state.

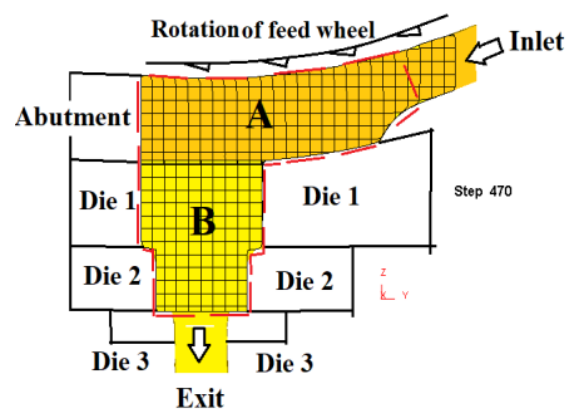

Figure 7. Partition of the plastic zone in CRE in A - the upset shearing region and $\mathrm{B}$ - the extrusion region.

\section{Partitioning of the plastic zone in two parts}

From our FEM-study of the CRE process, we observe that metal flow and deformations are quite different in the horizontal part of the plastic zone, where the metal has become upset into the gap between the feed-wheel groove and the top die, as compared to in the vertical zone, where the metal flows downwards through the three extrusion dies. Therefore, it seems appropriate to partition the plastic zone in two different regions $\mathrm{A}$ and $\mathrm{B}$ as shown in Fig.7. Region $A$ is the horizontal zone of metal, situated in the space between the feed-wheel, the abutment, and the top die. This is where the metal is upset during start-up of the process, and later deforms mainly in shear.
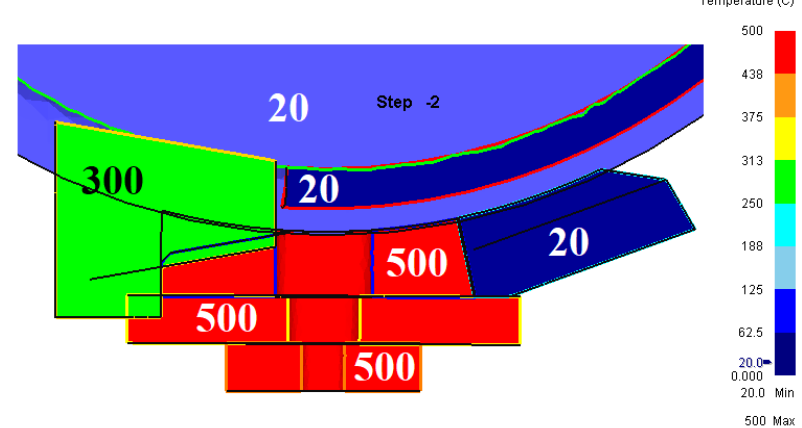

Figure 8. Initial temperature condition $\left({ }^{\circ} \mathrm{C}\right)$ in workpiece and dies in FEMmodel (500_HiFric).

In addition, there is the vertical part of the plastic zone, denoted $\mathrm{B}$ in the figure, in which metal flow resembles the flow in traditional forward extrusion.

\section{E. Thermal conditions in CRE}

Because the simulations are thermally coupled models, the exchange of heat between workpiece and tooling is computed. Thus, the models allow the temperature distributions in all bodies to be calculated. The predicted temperature field in the workpiece in a typical model is shown in Fig.9 (initial temperatures on tooling, see Fig.8).

Detail 1 in Fig.9, shows that the lump of metal pushed up in the end of the feed-rod, heats up to $\sim 240^{\circ} \mathrm{C}$. This is when the cold nose-end plugs the die exit. Later during CRE, see detail 2, the die has filled up with metal. Moreover, the upsetting action has now created a sufficiently large shear area between the workpiece material and the feed-wheel, in the upset zone A, to initiate reextrusion of the plug through the last die. The temperature in the exit of this die has now exceeded $360^{\circ} \mathrm{C}$.

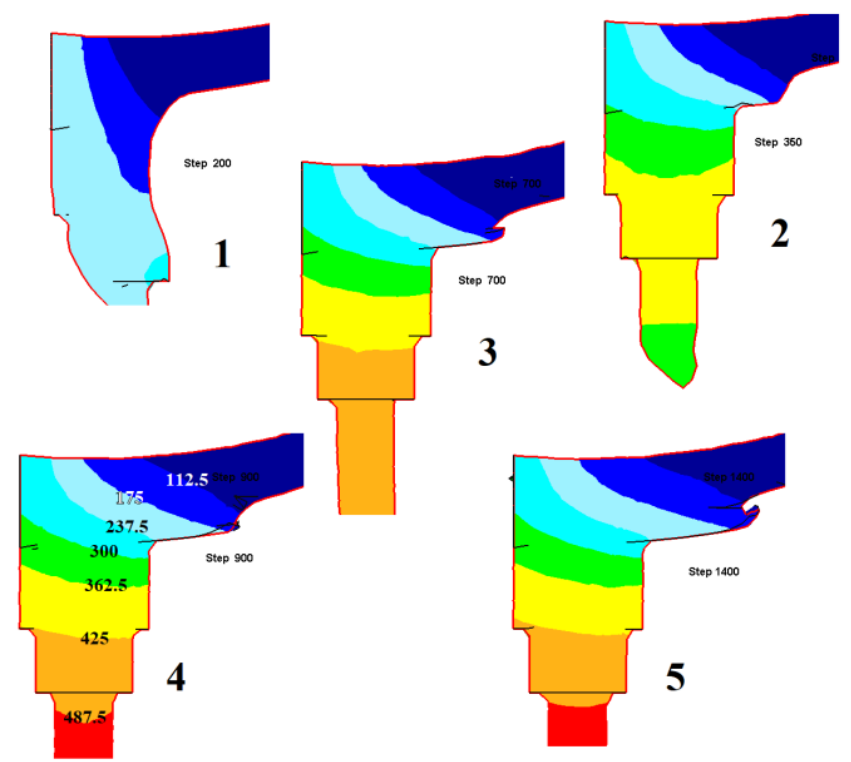

Figure 9. Evolution of temperature distribution in the plastic zone throughout the process (T500_HiFric). 
Proc. of the Eighth International Conference On Advances in Mechanical, Aeronautical and Production Techniques - MAPT 2018 Copyright (C) Institute of Research Engineers and Doctors. All rights reserved.

ISBN: 978-1-63248-147-4 doi: 10.15224/ 978-1-63248-147-4-19
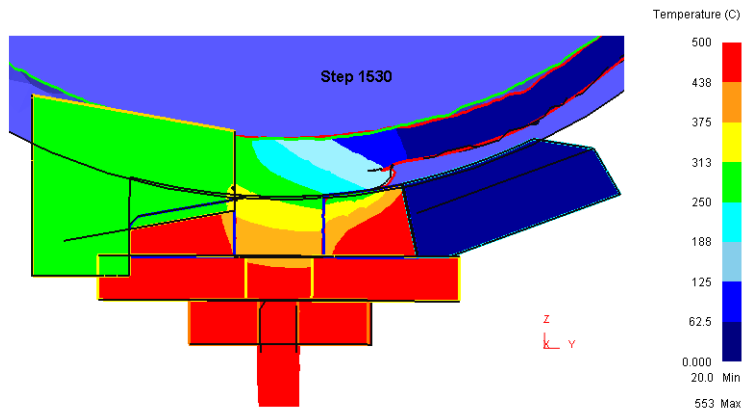

Figure 10. FE-predicted temperature distribution inside tooling and workpiece at end of simulation run.

Detail 3 and 4, in Fig.9, reveals that heating of the metal in the die cavities continues after the metal flow has become stable. Detail 4 represents the stage in the process when the temperature field in the plastic zone has reached steady state. From now on, there is no significant further heating on the workpiece in continued running of the simulation, see detail 5, in Fig.9.
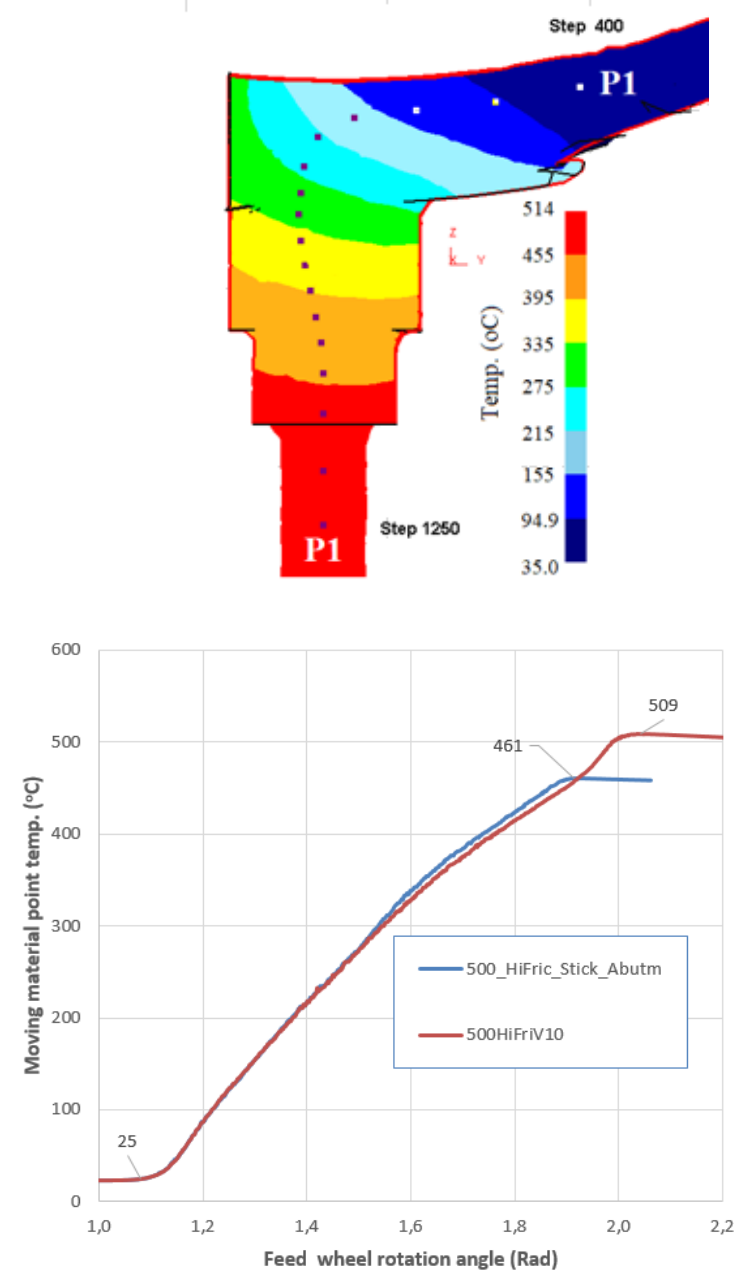

Figure 11. Material point flow-path through the plastic zone (top) and temperature rise in the travelling point (bottom).

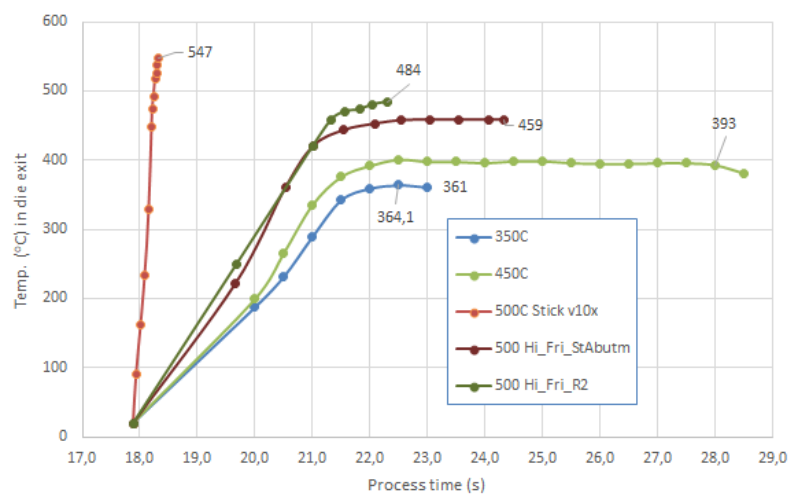

Figure 12. FEA-predicted temperature rise vs. time, in the exit of the last die (no.3) in CRE.

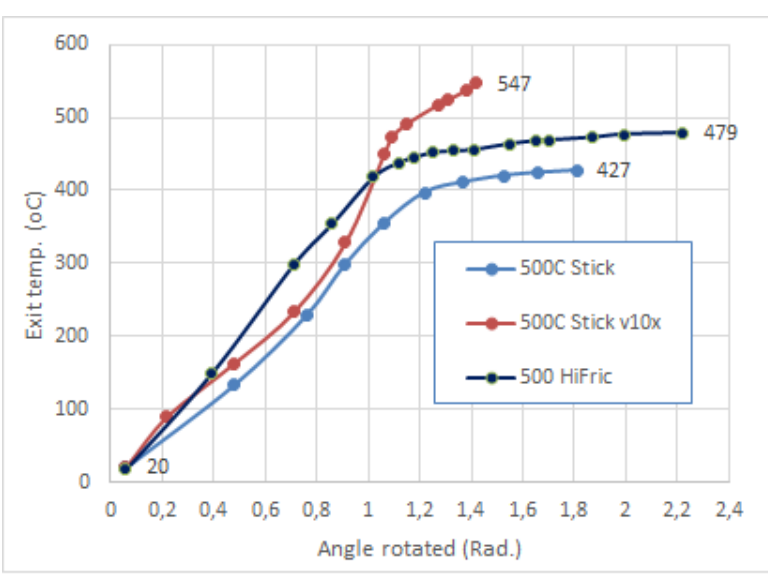

Figure 13. FEA-predicted temperature rise vs. rotated angle, in the exit of the last die.

Initial temperatures on the different bodies in the model, of course, affects the final temperature obtained. For the case shown in Fig.9 the initial temperature on the feedwheel and the feed-plate was $20^{\circ} \mathrm{C}$, the abutment $300^{\circ} \mathrm{C}$, and on the dies $500^{\circ} \mathrm{C}$, see Fig. 8 .

Thermal exchange between the dies and the workpiece, of course, increases with increasing process time, as there is no heat supply to the tool parts in the models, other than intrinsic heat generated in the process itself. Cooling effects on the dies are predicted significant during the rather short process time (7s) used; see Figs.8, 9 and 10. The top righthand part of the upper die cools the most, because cold metal from the upset rod flows against this die, here, at the process inlet, after the die cavities have filled up with metal. The abutment experiences considerably less temperature change, because the shearing process on the material in the upset shear zone (region A, in Fig.7), heats up the moving metal so that when it reaches the abutment, it has approximately the same temperature as the abutment, i.e., $300^{\circ} \mathrm{C}$. 
Proc. of the Eighth International Conference On Advances in Mechanical, Aeronautical and Production Techniques - MAPT 2018 Copyright (C) Institute of Research Engineers and Doctors. All rights reserved. ISBN: 978-1-63248-147-4 doi: 10.15224/ 978-1-63248-147-4-19

At the top in Fig.11, is shown the FEA-predicted particle path of a moving material point in the metal stream flowing through the plastic zone of CRE (point tracking). The figure at the bottom of Fig.11 shows that a temperature increase equal to that experienced in hot forming is reached along the flow path, with a final temperature above $450^{\circ} \mathrm{C}$, when the point leaves the die exit. Moreover, the temperature rise depends on the rotatay speed of the feed-wheel. Half the temperature rise is accommodated in the horizontal upset shear-zone $\mathbf{A}$, the other half in the extrusion zone $\mathbf{B}$. While temperature rise in $\mathrm{A}$ is mainly due to deformational heating due to shearing, heating in zone B is by combined deformational heating and thermal heat conduction from the hot dies surrounding the plastic zone.

The parameter that perhaps best describes the thermal conditions in a model is the die exit temperature. It was recorded in the simulations, and is shown in Fig.12 (vs. process time) and in Fig.13 (vs. rotation angle). The temperature in the die exit increases steadily with process time from a starting point of $20^{\circ} \mathrm{C}$. Finally, a stable temperature is reached in the die exit after $\sim 1 / 4^{\text {th }}$ rotation of the feed-wheel $(\sim 1.8 \mathrm{Rad})$ for the lowest rotational speed. This corresponds to a process time of approximately $5 \mathrm{~s}$. For the 10 times higher speed, however, it is required to rotate the wheel up to a larger angle to obtain a stable die exit temperature, and process time now is 10 times shorter. As depicted by the two figures, Fig.12 and Fig. 13, the die exit temperature depends strongly on the extrusion parameters varied in the simulations, i.e., temperature on the dies and the abutment, the reduction in the die, and the rotational speed of the feed-wheel.

\section{F. Feed-wheel torque and extrusion speed}

One can extract various extrusion parameters from a simulation. In CRE, it is interesting to know what the torque value is on the feed-wheel during filling of the die cavities, and later during the process. Other parameters are the velocity on the metal flowing out the die exit, and the vertical loads on the three dies in the die stack. These parameters were extracted in the simulation run at lowest feed-wheel speed. Resulting data are shown in the diagram in Fig.14.

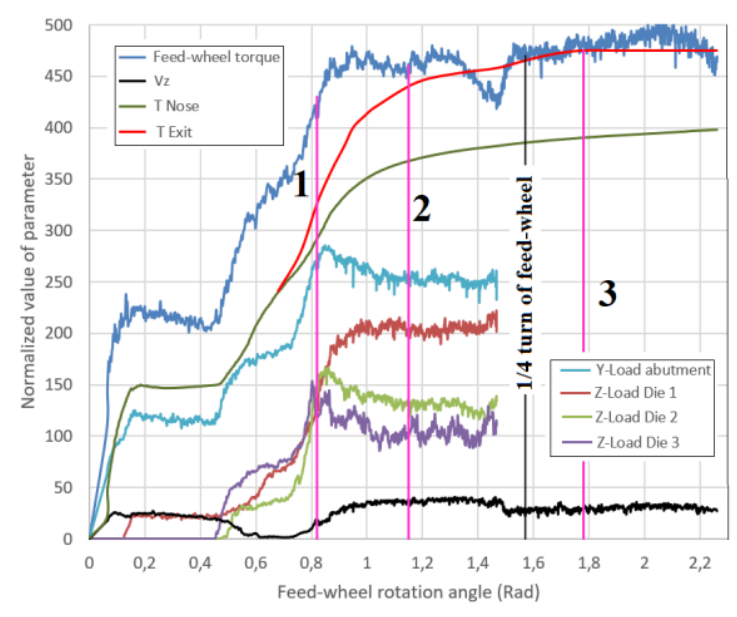

Figure 14. Extrusion parameters extracted from one of the simulations.
Three vertical lines in pink in the diagram shows what takes place as CRE proceeds. The first line (1) marks the instant when the die cavity have been completely filled-up with metal, and the cold metal plug in the die exit starts to move again. Before this, the velocity of the nose point of the extrusion has been at a minimum, but now increases again when the metal of the cold plug starts to move. The second line (2), in Fig.14, represents the stage when metal flow has become stable, after the release of the cold plug. At this instant, the torque on the feed-wheel has passed over its maximum, and so has the Y-load on the abutment and the Zload on the die no.2 and die no.3. The third line (3) represents the instant when the temperature in the die exit has ceased to increase, i.e., the temperature field in the process has become stable.

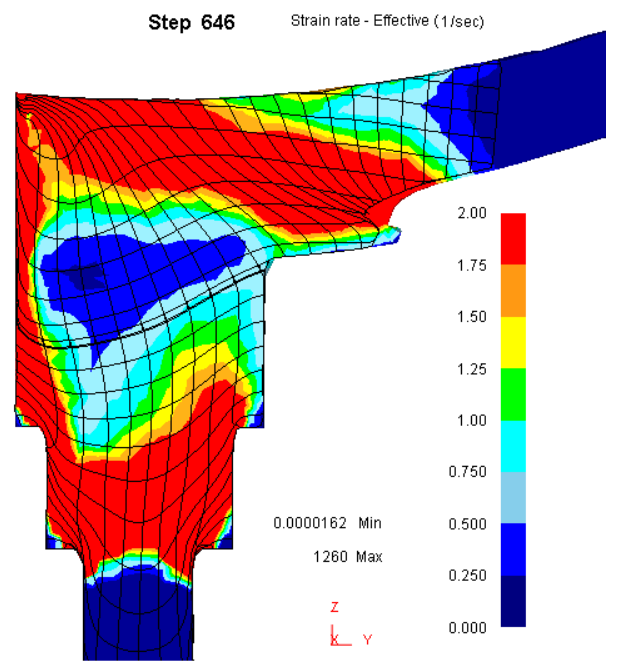

Figure 15. FEM-predicted strain-rate distribution inside the plastic zone, with deformed grid pattern included (500StickAbutm).

\section{G. Strain-rate distribution inside the plastic zone}

The strain-rate distribution in a longitudinal mid-section cut through the plastic zone is shown in Fig.15, as it was computed in one of our CRE-models. A deformed grid pattern has been super-imposed on top of this distribution.

The red colour areas in this figure are the regions where the plastic deformation intensity is the highest. Moreover, from the shape of the deformed grid elements one can judge whether the high intensity is due to shear deformation or elongation deformation.

\section{v. Discussion}

During our study, we have gained more knowledge and understanding of the mechanics of CRE. The FEM-models reveals some interesting information about the process conditions for the considered AA3003 alloy:

In the beginning, the metal from the feed-rod coined into the groove of the feed-wheel becomes squeezed against the abutment and causes build-up, by plastic deformation, of a lump of metal in the front end of the rod. With continued rotation of the wheel, this lump slips off from the surface of 
Proc. of the Eighth International Conference On Advances in Mechanical, Aeronautical and Production Techniques - MAPT 2018 Copyright (C) Institute of Research Engineers and Doctors. All rights reserved. ISBN: 978-1-63248-147-4 doi: 10.15224/ 978-1-63248-147-4-19

the abutment, becomes pushed downwards with "nose-like" shape into the middle of the die cavity, at the bottom of which, it hits the last die, and gets stuck for a while. Further deformation now takes place by lateral expansion of the nose, i.e., it grows like a balloon, blown up until it fills the cavity. The metal present in the die, now acts as plug of cold metal that blocks the die exit. When the feed-wheel tries to push more metal into the dies, the incoming feed-rod instead upsets, i.e., it spreads out laterally and fills up the gap between the groove of the feed-wheel and the top horizontal surface of the top die. When this happens, the contact zone between the feed-wheel and the upset metal region grows. Because of this, the ability of the feed-wheel to push metal into the die increases. The cold plug, stuck in the die exit, therefore starts to move again. With the movement, it starts to deform plastically, and heats up, partly due to heattransfer from the surrounding dies, but in addition, because of deformational heating of the metal pushed through the dies.

Some excessive length of the upset zone, represented by its maximum length, has been built-up to drive the cold plug forward, and as the plug heats and softens again, the length of the upset zone decreases upon further extrusion.

Finally, after the cold plug has been released, the flow velocity out the exit of the final die becomes stable, however, heating of the extruding material continues for an additional time, and then, finally the temperature field in the plastic zone also reaches steady state.

\section{vi. Concluding remarks}

When the metal has filled the die cavity in the Conform extrusion process, further metal flow takes place in the gap initially present between the feed-wheel and the die below, by means of upsetting of the coined rod from the wheel groove into this gap.

Because of this, an upset zone forms at the inlet side of the process, the length of which increases upon continued extrusion. When the upset zone has reached maximum length, overall flow becomes stable, so the amount of the metal fed into the inlet, equals the amount extruded out of the outlet in the process. Stable conditions are reached after approximately one-quarter rotation of the feed-wheel.

The plastic zone can be considered consisting of two parts. One part is the vertical region inside the extrusion dies, which we have chosen to name the extrusion zone. Deformations and metal flow here resemble the conditions in traditional forward extrusion. The second part is the horizontal upset zone in between the top die and the feedwheel groove. Deformations here are mainly in shear, but at the entrance to this region, the metal rod upsets as it is squeezed into the plastic zone.

At sufficiently high rotational speeds, hot forming conditions are obtained in the material extruded out of the die exit in the Conform extrusion process, even with the feed-rod rod kept at room temperature. Approximately onehalf the temperature rise is due to shearing taking place in the upset zone, the other half due to extrusion type of deformations in the extrusion zone.

\section{Acknowledgment}

The authors would like to thank MelTech equipment manufacture for sharing design concepts. One author (WZM) would acknowledge partial support from the Lowey Family Foundation through Lowey Professorship at Lehigh.

\section{References}

[1] Etherington, C., and Slater, H. K., The Extrusion of Aluminium and its Alloys by CONFORM Process, Proceedings of the third international aluminum extrusion technology seminar, 1984, p.31-38.

[2] Slater, H. K., and Coon, P. M. "Aluminum Extrusion by Conform An Update on Development Experience at the Springfields Laboratories of the UK Atomic Energy Authority." Proc. of $4^{\text {th }}$. Int. Al. Extrusion Technology Seminar. 1988, p.521-531.

[3] Song, L., Yuan, Y, and Zhimin Y. "Microstructural Evolution in Cu$\mathrm{Mg}$ Alloy Processed by Conform." International Journal of Nonferrous Metallurgy 2.03 (2013): 100.

[4] Hodek, J., and Kubina, T.. "FEM Model of Continuous Extrusion of Titanium in Deform Software." (2012): 1-7.

[5] Thomas, B. M., Derguti, F. and Jackson, M. (2017) Continuous extrusion of a commercially pure titanium powder via the Conform process, Materials Science and Technology, 33:7, 899-903

[6] Mitka, M., Gawlik, M., Bigaj, M., Szymanski, W., Continuous Rotary Extrusion (CRE) of Flat Sections from 6063 Alloy, Key Engineering Material, vol. 641; 2015; pp. 183-189.

[7] Mitka, M., Misiolek, W. Z., Grega, M. L., Bigaj, M., Szymanski, W., Continuous rotary extrusion of Magnesium alloy AZ91, Continuous Rotary Extrusion of Magnesium Alloys within the Institute for NonFerrous Metals, Light Metal Division, project report 7296/2914.

[8] Cho, J.R. and Jeong, H.S., CONFORM process: surface separation, curling and process characteristics to wheel diameter, Journal of Materials Processing Technology vol. 136; 2003; pp. 217-226.

[9] Kim Y.H et al, A study on optimal design for CONFORM process" Journal of Materials Processing Technology, vol. 80-81; 1998; pp. 671-675.

[10] Zhang, J. X., Luo, H., Jiang, S. F. and Fu, D., Microstructures and properties of $\mathrm{Al}-\mathrm{Mg}-\mathrm{SI}$ alloy overhead conductor by horizontal continuous casting and continuous extrusion forming process. Materials Science and Engineering: A, 649, (2016), 128-134.

[11] Zhao, Y., Song, B., Pei, J., Jia, C., Li, B., and Linlin, G. (2013). Effect of deformation speed on the microstructure and mechanical properties of AA6063 during continuous extrusion process. Journal of Materials Processing Technology, 213(11), 1855-1863.

[12] Wu, P.-Y. et al. "Effect of extrusion wheel angular velocity on continuous extrusion forming process of copper concave bus bar." Transactions of Nonferrous Metals Society of China 17.2 (2007): 280286.

[13] Peng, Y., Ruan, X., and Zuo, T. "Defect prediction during CONFORM process by FEM." Journal of materials processing technology 45.1-4 (1994): 539-543.

[14] Yun, X., et al. "Continuous extrusion and rolling forming velocity of copper strip." Transactions of Nonferrous Metals Society of China 23.4 (2013): 1108-1113.

[15] Katajarinne, T., Manninen, T. and Ramsay, P. "Numerical simulation of flash formation in continuous rotary extrusion of copper." Journal of materials processing technology 177.1 (2006): 604-607.

[16] Manninen, T., Ramsay, P., and Korhonen, A. S. "Three-dimensional numerical modeling of continuous extrusion." advanced technology of plasticity (2002): 439-444

[17] Hodek, J., Kubina, T., and Dlouhy, J.. "FEM model and experimental production of titanium rods using Conform machine." (2013): 15-17.

[18] Rajendran, N., "Numerical Simulation of Continuous Rotary Extrusion of Magnesium AZ91 Alloy", MS Thesis, Mechanical Engineering and Mechanics, Lehigh University, 2016.

[19] Rajendran, N., Valberg, H., and Misiolek, W. Z., "The FEM simulation of continuous rotary extrusion (CRE) of aluminum alloy AA3003." AIP Conference Proceedings. Vol. 1896. No. 1. AIP Publishing, 2017 